\title{
A situación actual da lingua galega ${ }^{1}$
}

\author{
FRANCISCO FERNÁNDEZ REI
}

Instituto da Lingua Galega

\section{XEOGRAFÍA E DEMOGRAFÍA}

$\mathrm{O}$ territorio linguiístico do galego moderno comprende a Galicia administrativa $\left(29.424 \mathrm{~km}^{2}\right.$ ) e as comarcas estremeiras da franxa exterior (A Terra Navia-Eo de Asturias, O Bierzo occidental de León e As Portelas de Zamora). As formas sen ditongo pedra e porta e as formas canciois e ter sen - $\mathrm{N}$ - latino intervocálico delimitan o galego oriental do asturiano e leonés occidental, con piedra, puerta, canciones e tener; por outra parte, a ausencia de vocais nasais e de sibilantes sonoras en galego e a súa presencia en portugués permiten establece-la fronteira lingüística co portugués setentrional (Fernández Rei, 1990 a, 18-30).

Segundo o censo (provisorio) de 1996 a poboación de Galicia era de 2.743.999 habitantes ${ }^{2}$, ós que cómpre engadir preto de 80.000 persoas das comarcas estremeiras onde o galego é lingua propia (45.000 na Terra Navia-Eo, 30.000 nos Ancares e no Bierzo occidental e 1.800 nas Portelas) ${ }^{3}$. Demografi-

\footnotetext{
' Neste traballo sigo un artigo da miña autoría redactado en 1993 e recentemente editado en versión francesa (Fernández Rei 1997). As modificacións afectan, fundamentalmente, ós apartados relativos á situación do galego na actualidade co fin de dar unha mostra o máis actualizada posible da vitalidade etnolingüística galega.

${ }^{2}$ A poboación galega era de 2.895 .469 no censo de 1978 e baixou a 2.731 .669 no censo de 1991 (un descenso de 163.000 habitantes). Datos tirados de Xunta de Galicia $(1997,42)$.

${ }^{3}$ Segundo o censo de poboación do INE a poboación de dereito a 1 de xaneiro de 1995 era de 48.214 habitantes nos 18 concellos da Terra Navia-Eo, incluídas as parroquias orientais dos concellos de Navia, Allande, Villallón e Ibias onde se fala ben unha variedade máis asturiana ca galega. Segundo o mesmo censo, nos 16 concellos do Bierzo onde a lingua propia é a galega (incluído o de Vega de Espinaredo cunha zona de galego de transición ó leonés) a poboación de dereito en 1995 era de 28.151 habitantes, ás que cómpre engadir parte da poboación de Camponaraia e Priaranza (4.267 en total) e tamén sumar núcleos galegófonos do concello de Ponferrada.

A zona das Portelas de Zamora está a ter un proceso acelerado de despoboamento e de envellecemento. Segundo o censo de poboación do INE de 1981 nos concellos de Porto, Pías, Lubián e Hermisende vivían 2.173 persoas de dereito e 2.031 de feito, ás que habería que engadir 184 de dereito e
} 
camente, a poboación de Galicia está espallada en 31.894 entidades de poboación, que representan case a metade do total das existentes no Estado Español. Delas soamente sete son cidades de importancia (Ferrol, A Coruña, Santiago de Compostela, Pontevedra, Vigo, Lugo e Ourense), ás que hai que sumar un número grande de vilas (de centos ou de miles de habitantes) e un elevadísimo número de aldeas, moitas deles con escasa poboación na actualidade.

Fóra de Galicia viven actualmente máis 550.000 galegos de orixe en idade adulta (200.000 no Estado Español, 180.000 en Europa e 175.000 en América), segundo datos dunha investigación inédita de Monteagudo Romero, que ten en conta as taxas de emigración, de mortalidade e de retornados. Entre 1860 e 1910 emigraron a Sudamérica 500.000 galegos e unha cantidade semellante entre 1915 e 1930 , cifra que descendeu a 350.000 entre 1946 e 1965. Posteriormente, a emigración realizouse, fundamentalmente, ás zonas industrializadas de Europa, con 200.000 emigrantes entre 1960 e 1977 (Sixirei, 1988).

\section{ESPLENDOR, DECADENCIA E REEMERXENCIA DO GALEGO}

\subsection{A Idade Media}

Na historia de Galicia ten unha enorme importancia o "descubrimento" do sartego do Apóstolo Santiago a comezos do séc. IX, feito que potenciará a ideoloxía da reconquista cristiá e favorecerá a puxanza política, económica e cultural de Santiago de Compostela. As vilas van adquirindo importancia, producíndose no séc. XII o primeiro alzamento dos burgueses composteláns contra o arcebispo Xelmírez; pero a burguesía urbana galega comezou a decaer desde o reinado de Fernando III (1230-1253), que atacou o poder dos concellos e enviou forasteiros a gobernaren Galicia.

No que atinxe á situación lingüística, o latín -a pesar de que o pobo xa non o entendía-, foi a lingua literaria e relixiosa e tamén a dos actos xurídicos e administrativos durante boa parte da Idade Media en toda a Península Ibérica. En Galicia este bilingüismo cultural mantívose ata o séc. XIII.

Os séculos XIII-XIV constitúen unha etapa de esplendor para o galego, que se converteu na lingua lírica por excelencia da Península, do que é boa proba o importantísimo corpus lírico medieval formado polas cantigas de amigo, de amor, de escarnio e maldicir e a colección de miragres das Cantigas de Santa María do rei Afonso X o Sabio. Polo que respecta á prosa, na Idade

183 de feito do lugar de Calabor (en Pedralba de la Pradería), onde o galego tamén é lingua propia. No censo de poboación e vivendas de 1991 o número de habitantes dos catro concellos das Portelas baixara 1.711 de dereito e 1.635 de feito. 
Media escríbense algunhas obras de carácter histórico, didáctico ou literario, con atención ós grandes temas da literatura europea da época, xeralmente traducidas do castelán ou do latín.

Daquela o galego era lingua de uso normal para toda a poboación, empregándose a nivel escrito en calquera acto xudicial e administrativo. Ata mediados do séc. XVI aínda se redactan en galego actas e contratos de concellos e gremios, testamentos, preitos e tratados legais. Pero a penetración do castelán inciada no reinado de Fernando III (séc. XIII) acentuarase no séc. XIV despois da loita pola coroa de Castela entre Pedro I e Henrique II. Coa victoria deste último, a derrotada nobreza galega empeza a ser substituída por nobres casteláns, proceso que se consumará plenamente no reinado dos Reis Católicos (séc. XV) ó seren ocupados os postos clave da administración e da Igrexa galega por xente de fóra, que emprega exclusivamente o castelán. A nobreza e o clero galegos seguen os pasos marcados pola nobreza castelá instalada en Galicia, converténdose nun núcleo diglósico asimilado ${ }^{4}$.

\subsection{SÉculos XVI-XVIII}

A partir da etapa renacentista, mentres outras linguas románicas se estandardizan e se fortalecen como linguas estatais, o galego perde toda relación coa cultura escrita, quedando relegado a usos orais e ámbitos rurais e familiares. $\mathrm{O}$ galego falábao a inmensa maioría da poboación, pero unha minoría de lingua castelá posuía o poder económico, político e cultural en Galicia, do que é proba o feito de que durante os séculos XVI-XVII soamente foran galegos o $2 \%$ dos maxistrados da Real Audiencia do Reino de Galicia, porcentaxe que subiu ó 15\% no séc. XVIII (Villares, 1984, 100-1). A Real Audiencia era o órgano de Goberno da Monarquía central, con atribucións administrativas, gobernativas e xudiciais.

A Igrexa católica tivo un papel negativo moi importante no desenvolvemento do galego ó marxinalo das prácticas relixiosas. A administración dos sacramentos e os rezos colectivos (rosarios, novenas...) facíanse —e aínda se fan maioritariamente- en castelán, á vez que as oracións diarias da devoción persoal se ensinaban neste idioma. Nos países da Europa occidental onde existían situacións lingüísticas semellantes á galega como é o caso de Cataluña, Euskadi ou Bretaña, o clero permaneceu fiel á lingua propia do seu pobo.

A isto hai que engadi-lo feito de que o sistema escolar nestes séculos dependía da Igrexa, que usaba o latín e o castelán para educar relixiosamente un pobo galegofalante. Isto explícase porque os cargos eclesiásticos, practicamente todos, províanse con xente non galega. Os datos da castelanización da

${ }^{4}$ Cf. Monteagudo Romero (1985, 105) e Chacón (1979). 
xerarquía eclesiástica en Galicia son ben elocuentes: entre 1500 e 1830 só houbo dous bispos galegos na diócese de Lugo, un na de Tui, dous na de Mondoñedo, cinco na de Ourense e outros cinco na de Santiago (Vázquez Cuesta, 1980, 707).

Neste séculos escuros en que o galego se foi desprestixiando socialmente existe, non obstante, unha tradición dignificadora e reivindicativa nas clases máis instruídas do país (Monteagudo, 1991; Freixeiro Mato, 1997, 56-70). A finais do Séc. XVI o cabido compostelán protesta por concedérenselle os mellores beneficios ós que descoñecían o galego e no séc. XVII algúns autores compoñen poesía en galego. No séc. XVIII hai ilustrados preocupados polo estudio e pola recuperación da conciencia idiomática do galego entre os que salienta o Padre Sarmiento, que nos seus escritos denunciou a marxinación social do galego por non ser usado como lingua de alfabetización, da administración e da Igrexa. A súa obra constitúe o inicio da lingüística galega científica.

Neste séculos de decadencia consolidáronse os principais trazos caracterizadores da lingua galega actual que a afastan da portuguesa, coa que comparte unha fase común na Idade Media, á vez que se orixinaron os principais fenómenos lingüísticos que caracterizan as áreas lingüísticas do galego moderno. Portugal, con institucións políticas de seu e cunha capital política e cultural, difundiu unha norma idiomática única dentro do territorio do seu estado, mentres que en Galicia a lingua continuou a súa evolución, mantendo formas arcaizantes, innovando ou desnaturalizándose pola constante presión do castelán.

\subsection{O SÉcUlo XIX: o REXURDIMENTO}

A invasión e conquista da península Ibérica polas tropas de Napoleón (1808-10), coa conseguinte resposta popular antifrancesa, supuxo o colapso momentáneo do estado centralizador. En 1808 formouse a Xunta Soberana do Reino de Galicia, que chamou á loita contra os invasores franceses. Un dos medios de axitación máis populares foron panfletos e folletos, escritos en galego, cos que se invitaba á poboación a participar na resistencia.

A partir da terceira década do século vaise consolidando o novo réxime, baixo a forma de Estado monárquico autoritario, con predominio liberal-conservador pero fortemente militarista e centralizado. Entre as medidas centralizadoras destaca a creación das provincias como principais unidades administrativas en substitución das antigas rexións (coma o Reino de Galicia) e a creación dun aparato escolar independente da Igrexa católica, que tiña entre os seus obxectivos acada-la uniformidade lingüística en todo o Estado, coa imposición do castelán e a marxinación das linguas periféricas (galego, catalán e euskera), do que é proba a promulgación dun Real Decreto en 1902 que prohibe o uso destas linguas na escola. Esta política continuará, con maior ou menor 
intensidade e c5ase sen interrupción, ata a promulgación da recente Constitución Española de 1978 (García Negro, 1991, 207-39).

Como reacción ó centralismo estatal uniformizador, na segunda metade do séc. XIX vaise artellando unha corrente de pensamento galeguista, que se desenvolve en dúas fases: o provincialismo (de 1840 a 1885) e o rexionalismo (de 1885 a 1915). Este galeguismo dará orixe, no primeiro tercio do séc. XX ó nacionalismo. Na segunda metade do séc. XIX ten lugar o renacemento e a reemerxencia do galego como lingua literaria, o Rexurdimento (Hermida, 1992), en especial coa publicación dos Cantares Gallegos (1863) de Rosalía de Castro (1837-85). Esta poetisa e os tamén poetas Eduardo Pondal (1835-1917) e M. Curros Enríquez (1851-1908) constitúen as 'tres coroas' en que se asentou o devandito Rexurdimento. Nesta época aparecen as primeiras gramáticas e diccionarios do galego, destacando as contribucións de X. A. Saco Arce e Marcial Valladares. E tamén son destes anos os primeiros chamamentos para a creación dunha academia da lingua galega, que se acabaría fundando en 1906 baixo o lema Colligit, expurgat, innovat ('Recolle, depura, innova').

\subsection{Do Posrexurdimento ó Estatuto de 1936}

Nos últimos 90 anos houbo grandes cambios tanto na economía como na sociedade mesma. Nos censos de 1900 o $88,7 \%$ da poboación galega era rural e o 6,4\% urbana, e só o 4,7\% vivía en vilas (entidade intermedia entre a cidade e aldea), pero na actualidade máis da metade da poboación reside nas cidades ou nas súas áreas de influencia.

A economía da Galicia de comezos do séc. XX era case exclusivamente agrícola, cunha agricultura practicamente feudal, que só producía para o autoconsumo e o pagamento dos foros. A escasa industrialización reducíase á fabricación de tabacos e á importante industria conserveira -que empregaban case exclusivamente mulleres-, e á fabricación de fiados, curtidos, papel, cerámica e pouco máis. A febleza da industria explica a escasa implantación dos movementos obreiros (CNT, UGT), en contraste coa fortaleza das organizacións agrarias, mercé ás cales se redimiron os foros entre 1910 e 1930. Isto supuxo un gran cambio social, porque os foros eran un atranco para o desenvolvemento da agricultura.

O ano 1916 é transcendental na evolución do galeguismo, coa formación da Irmandade dos Amigos da Fala na Coruña, á que seguirían nas semanas seguintes as Irmandades de Santiago, Monforte, Pontevedra, Ourense e Vilalba (G[onzález] Beramendi/Núñez Seixas, 1995, 95). As Irmandades da Fala, aínda que formulan uns obxectivos fundamentalmente culturais (defensa e difusión do galego a través dunha práctica de emprego sistemático do mesmo, do que é boa mostra o seu órgano de expresión A Nosa Terra, editado integramente en galego desde a súa aparición en novembro de 1916), vaise virando 
cara á acción política (I Asemblea Nacionalista de Lugo, 1918), que desembocará na fundación do Partido Galeguista en 1931, ano da proclamación da II República Española.

Este partido foi un instrumento fundamental para a consecución do Estatuto de Autonomía de Galicia (xuño de 1936), onde se recoñecía a cooficialidade do galego co castelán. Na actividade cultural e política da Galicia dos anos vinte e trinta teñen un papel sobranceiro os intelectuais que constitúen a Xeración Nós, que usan o galego de forma exclusiva ou preferente en todo tipo de escritos (literarios, científicos, políticos...), o que supuxo un forte progreso na elaboración do galego moderno. E en galego escriben de etnografía, xeografía, arqueoloxía, prehistoria e ciencias naturais e aplicadas os integrantes do Seminario de Estudos Galegos (1923), a empresa científica e cultural máis destacada das levadas a cabo antes de 1936.

\section{A SITUACIÓN DO GALEGO NA ACTUALIDADE}

A guerra civil (1936-39) supuxo un freo e un retroceso no proceso de modernización, polo que o cambio socioeconómico non se produciu ata os anos 60 , cando progresivamente se foi substituíndo na agricultura o tradicional policultivo de subsistencia por unha agricultura especializada, fundamentalmente encamiñada ó sector gandeiro: producción de carne e de leite. $\mathrm{Na}$ industria, os cambios maniféstanse na construcción de plantas transformadoras de productos agrarios e cárnicos, no crecemento da industria naval en Vigo e Ferrol e na instalación de industria de 'enclave' por grupos monopolistas que procuran en Galicia materias primas de doada explotación, enerxía barata e man de obra abundante.

Non obstante, a Galicia dos anos 60 e 70 aínda está atrasada economicamente en relación co resto do Estado Español: en 1975 só o $22 \%$ da poboación activa galega estaba empregada no sector secundario (industria e construcción), mentres que no resto do Estado esa cifra acadaba o 36\% (Santamarina/Fernández Rei, 1992, 25). A mediados dos 70 hai unha crise de crecemento provocada pola caída da demanda para os principais sectores, crise que se agudiza a finais do 80 coa reconversión industrial que afectou moi gravemente ó sector naval, así como coa entrada do Estado Español na CEE (hoxe UE), que afectou á pesca, á agricultura e á gandería.

Polo que respecta á situación sociolinguística, a extensión da escolarización e dos novos medios de comunicación audiovisuais, con novos valores culturais, vai introducindo o castelán en tódolos recantos do país. Antes dos anos 60 , entre os escasos signos de resistencia contra o acelerado proceso de castelanización de Galicia, cómpre salienta-la fundación da Editorial Galaxia (1950). Na década dos 60 reavívase a vida cultural coa creación dunha extensa rede de asociacións culturais nas principais cidades e vilas, que teñen como 
principal obxectivo a defensa do galego. Reanímase a actividade politica clandestina das forzas democráticas, entre as que destacan o Partido Comunista, que en 1968 creará unha organización autónoma para Galicia, e as dúas tendencias da esquerda nacionalista, o Partido Socialista Galego (1963) e a Unión do Pobo Galego (1964). O nacionalismo político e sindical será nos anos 70 o dinamizador da normalización do uso do galego (Fernández Rei, 1990b).

\subsection{Galego, lingua cooficial}

O modelo de cooficialidade das linguas consagrado na Constitución Española (1978) combina a cooficialidade territorial coa individual. Os outros dous textos legais básicos son o Estatuto de Autonomía de Galicia (1980) e a LNL (Lei de Normalización Lingüística, 1983). O primeiro supuxo a institucionalización dun Parlamento e dun Goberno autónomos, practicamente galeguizados nas publicacións oficiais e na lingua usada publicamente polos responsables políticos. Nos organismos oficiais dependentes do Estado a lingua de uso normal en Galicia segue sendo a castelá, a pesar da cooficialidade.

O Estatuto de Autonomía no seu artigo 5 declara que o galego é a lingua propia de Galicia, compromete os poderes públicos coa súa promoción e senta o principio de non discriminación dos cidadáns por materia de lingua. A $L N L$ ten como obxectivo equipara-lo galego co castelán, para o que senta o principio da plena oficialidade do galego: toda actuación administrativa ou xudicial será válida e producirá os seus efectos calquera que sexa a lingua oficial empregada.

A $L N L$ supuxo un considerable avance no terreo legal e institucional, pero existen limitacións pola falta de claridade dos sucesivos gobernos autónomos nos obxectivos alcanzables e nos medios utilizables. Existe unha Dirección Xeral de Política Lingüística encargada da planificación e do control das medidas tendentes a cumpri-los obxectivos que marca a LNL. Non se pode dicir que estes obxectivos se cumprisen, entre outras razóns, porque a devandita Dirección Xeral foi concebida como un departamento da Consellería de Educación con moi pouca posibilidade de actuación fóra do ámbito educativo. Ademais, nestes momentos aínda carece de persoal con formación sociolinguística para levar a caboa planificación lingüística que permita a plena normalización social do uso da lingua galega.

\subsection{O GALEGO NA SOCIEDADE}

Segundo os datos do Mapa Sociolingüístico de Galicia (Fernández Rodríguez/Rodríguez Neira 1994, 1995a, 1995b) a sociedade galega ten unha com- 
petencia alta no dominio das destrezas lingüísticas en lingua galega, xa que o $97,1 \%$ da poboación o entende moito ou bastante, o 86,4\% sabe falalo, o 45,1\% leo ben ou bastante ben e o $27,1 \%$ domina moito ou bastante a súa técnica escrita 5 .

Así e todo, estas altas porcentaxes de dominio de destrezas lingüísticas non se corresponden coa presencia do galego como lingua inicial e como lingua habitual da poboación, pois só o $60,3 \%$ ten o galego como lingua inicial, mentres que o $68,6 \%$ fala só ou preferentemente en galego. Estas cifras globais varían significativamente de termos en conta a poboación atendendo a factores como a idade, a clase social, os estudios ou o hábitat.

As porcentaxes máis altas do galego como lingua inicial $(80,6 \%)$ e como lingua habitual $(84,7 \%)$ danse nos falantes de máis de 65 anos e as máis baixas no sector comprendido entre os 16 e os 25 anos, cun $36,7 \%$ en lingua inicial e un $46,5 \%$ en lingua habitual. De tomárense como base de análise as clases sociais obtemos que a clase media-alta é a que posúe en menor grao o galego como lingua inicial $(28,1 \%)$ e como lingua habitual $(35,3 \%)$, mentres que é na clase baixa onde está a maior porcentaxe dos que aprenderon a falar en galego $(75,3 \%)$ e dos que o falan $(83 \%)$.

Verbo do hábitat de nacemento, a presencia do galego como lingua inicial e como lingua habitual mingua a medida que pasamos dunha zona rural sen un centro de servicios $(85,8 \%$ e $89,7 \%)$ a unha zona rural con centro de servicios $(66,7 \%$ e $78,6 \%)$, ás vilas $(51 \%$ e $65,4 \%)$, ós núcleos periurbanos $(61,5 \%$ e $64,6 \%$ ) e ás cidades $(16,7 \%$ e $37,7 \%)$. E verbo da presencia do galego como lingua habitual en relación co nivel de estudios dos falantes, a porcentaxe máis alta de persoas que falan só ou preferentemente galego dáse entre as que non posúen ningún tipo de estudios $(95,8 \%)$, as que teñen estudios primarios incompletos $(86,9 \%)$ ou completos $(72,8 \%)$. Pola contra, as persoas que máis usan o castelán son as que posúen unha carreira de grao superior $(71 \%)$, unha carreira de grao medio $(63 \%)$ ou o bacharelato $(60,1 \%)^{6}$.

De todos estes datos tírase a conclusión que, malia o constante descenso de persoas que teñen o galego como lingua inicial e como lingua habitual, a lingua de Rosalía, de Castelao e de Méndez Ferrín aínda segue a ser maioritaria en Galicia. Así e todo, o diferente nivel de uso que fan dela as persoas segundo o estamento, a xeración, o nivel de estudios e o hábitat fai que se lle asigne as etiquetas de lingua de vellos, rural, de clases medias-baixas e de persoas que só posúen estudios básicos. O castelán, pola contra, é a lingua común dos cidadáns, da xente nova e das persoas de alto nivel educativo e económico.

A situación de Galicia é un exemplo de bilingüismo substitutorio, con diglosia en moitos dos galegofalantes. Trátase de diglosia de adscrición (Rojo 1981,270 ss; 1982, 94-5), aínda que xa se entrou nunha clara situación de

\footnotetext{
${ }^{5}$ Cf. Fernández Rodriguez/Rodríguez. Neira (1995b:1).

${ }^{\circ}$ Cf. Fernández Rodríguez/Rodríguez Neira (1995b:1) e (1995a:94).
} 
diglosia conflictiva (Fernández 1978, 390). Agora ben, existe unha reacción social que reclama unha rectificación desta situación para coloca-lo galego no lugar que lle corresponde como lingua propia de Galicia. Proba disto é o labor de diferentes asociacións cidadás (a Mesa pola Normalización Lingüística, a Asociación de Funcionarios pola Normalización Linguística, a Plataforma polo Galego na Informática, a Plataforma polo Ensino en Galego, etc.), que naceron ante a pasividade e o desleixo do goberno autonómico verbo da extensión do uso do galego e o non cumprimento da LNL.

Estas asociacións nos últimos anos estimularon os sectores sociais máis sensibles na reivindicación dos seus dereitos lingüísticos, promoveron campañas de normalización en ámbitos en que a presencia do galego era inexistente ou deficitaria como ocorría no comercio, nas empresas ou na publicidade, e asemade denunciaron as transgresións legais tanto dos poderes públicos como dos privados (Recalde 1997: 27). A estas asociacións hai que engadir organizacións políticas e sindicais, especialmente as ligadas ó movemento nacionalista, que promocionan o uso do galego ó usáreno sistematicamente en tódalas súas publicacións e mais nas intervencións públicas.

\subsection{O GALEGO NO ENSINO}

No ensino houbo iniciativas positivas, pero a ausencia de planificación restoulles eficacia. En poucos anos pasouse da permisividade do ensino da lingua (Real Decreto 1981/1979 de 20 de xullo) á súa obrigatoriedade (Decreto $135 / 1983$ de 8 de setembro); e máis adiante (Orde de 1 de marzo de 1988) previuse o emprego do galego como lingua vehicular polo menos na área de Ciencias Sociais nos ciclos medio e superior de EXB e en dúas materias por curso no Bacharelato e no COU, a escoller entre Xeografía, Historia, Ciencias Naturais, Física e Química, Matemáticas, Informática e Filosofía. Na FP as dúas materias elíxense entre Formación Humanística, Prácticas, Tecnoloxía e Matemáticas.

Para o currículum educativo que derive da reforma que se está a implantar na actualidade, é obrigatorio dispensar en galego a docencia das materias de dúas áreas de coñecemento (unha delas a do medio natural, social e cultural) no segundo e no terceiro ciclo da Educación Primaria, mentres que na Educación Secundaria obrigatoria se ensinarán en galego as materias da área de Ciencias Sociais, de Ciencias Naturais, a optativa de Ciencias Medioambientais e da Saúde e a optativa do centro. Nos distintos bacharelatos é obrigatorio impartir en galego unha materia común (Filosofía en $1^{\circ}$ e Historia en $2^{\circ}$ ), unha en $1^{\circ}$ ou dúas en $2^{\circ}$ específicas de cada bacharelato e tres materias optativas (Ética e Filosofía do Dereito, Introducción ás Ciencias Políticas e Socioloxía e Historia e Xeografía de Galicia). Por outra parte, o galego é a lingua da administración educativa de Galicia, polo que as actuacións desta se realizarán normalmente en galego. 
A pesar da LNL, a escola está a ser un elemento máis castelanizador que galeguizador. Boa proba disto son as altas porcentaxes de alumnos que teñen o galego como primeira lingua, pero que no recinto escolar sempre ou case sempre empregan o castelán na escrita $(89 \%)$ e/ou cos profesores $(51,4 \%)$, tal como se tira dos datos do Mapa Sociolingüístico de Galicia (Recalde 1997, 25).

Coa actual lexislación autonómica non se procura un sistema educativo específico para Galicia que teña o galego como lingua do ensino, senón que se lexisla para acadar unha presencia do galego que vaia un pouco máis alá do seu uso na docencia das materias de lingua e de literatura galega. Todo na liña da política lingüística do "bilingüismo harmónico" que defende o actual goberno autonómico galego, (utópico) bilingüismo que acabará por debilitar aínda máis o galego e por favorece-lo castelán, abondo xa favorecido constitucionalmente.

O galego é lingua oficial nas tres universidades de Galicia, pero o seu uso é escaso tanto por parte do profesorado como do alumnado. Na Universidade de Santiago soamente a administración pode dicirse que está galeguizada, co uso practicamente exclusivo do galego. Polo que respecta ós centros, a Facultade de Ciencias da Información compostelá posiblemente sexa hoxe a máis galeguizada na docencia, pois case tódolos profesores usan o galego nas aulas 7 .

\subsection{O GALEGO NOS MEDIOS DE COMUNICACIÓN}

A ausencia do galego nestes medios na etapa franquista e o analfabetismo en galego dos adultos son factores contrarios á galeguización da prensa. Nas publicacións non diarias só hai un semanario integramente en galego, $A$ Nosa Terra. Periódico galego semanal (1977) e varias publicacións de circulación comarcal ou local con distinta periodicidade ( $A$ Peneira, $O$ Miñor, $O$ Norte, etc.), xunto con revistas de periodicidade máis espaciada como Tempos Novos. Revista mensual para o debate (1997), a bimensual Encrucillada. Revista galega de pensamento cristián (1977), as trimestrais Grial. Revista galega de cultura (1963), Revista Galega de Educación (1986), A Trabe de Ouro. Publicación galega de pensamento crítico (1990) ou Análise empresarial..

$\mathrm{Na}$ prensa diaria o uso do galego é escaso, reducido a espacios de comentaristas, colaboracións literarias e política galega e local. Na prensa diaria soamente existe un diario integramente en galego, $O$ Correo Galego (6 de xaneiro de 1994), fronte a nove diarios en castelán editados en Galicia e as edicións para Galicia dos xornais madrileños El Mundo e El País. Nun estudio de Hermida $(1995,77)$ sobre o uso do galego na prensa diaria dende o 1977 a 1993

${ }^{7}$ Sobre o uso do galego nos distintos sectores do ensino realizáronse varios informes nos útimos anos. Cf. Rubal Rodríguez/Rodríguez Neira (1987), Rodríguez. Neira/López. Martínez (1988), Rubal. Rodriguez/Veiga Martínez/Arza Arza (1992). 
apréciase un aumento no número de informacións presentadas en galego dentro dunhas porcentaxes que non superan o $6 \%$ do total das informacións fornecidas.

En 1986 comezaron a funciona-las cadeas públicas de Radio Televisión Galicia, dependentes da administración autonómica: a radio emite ininterrompidamente en galego, mentres a TVG ten actualmente máis de 90 horas semanais con programación integramente en galego. A primeira canle de TVE en Galicia emite de luns a venres aproximadamente unha hora diaria en galego, programación que se remonta a mediados dos 70 . O resto da programación da TVE 1 realízase en castelán. $E$ integramente nesta lingua emiten as outras catro canles de ámbito estatal (Antena 3, Canal +, Tele 5, TVE 2). A programación propia das televisións locais é toda ou case toda en galego, con algunha excepción como as TV da Coruña, de Vigo ou de Ponteareas que só emiten en castelán.

As radios estatais emiten só en castelán con algunha excepción como RadioVoz, con algunha emisión en galego para Galicia ou para ámbitos territorios máis reducidos, ou Radio Uno de Radio Nacional de España, que emite en castelán pero cunha dúas horas e media de programación en galego. A Radio Galega, como xa se indicou, emite as 24 horas en galego. As radios locais de propiedade municipal fano en galego, con algunha excepción, mentres que as privadas fano en castelán con algunha excepción (Hermida 1998).

\subsection{A Igrexa CATÓLICA}

Xa se indicou anteriormente que a Igrexa foi un activo axente castelanizador nunha sociedade que usaba (e aínda usa) maioritariamente o galego. Cando nos anos 60 o Concilio Vaticano II impuxo a celebración dos ritos nas linguas vernáculas, o castelán foi o escollido en Galicia; e de feito, son moi recentes a versión oficial en galego do Misal Romano (1987) e a da Biblia (1989).

Segundo un estudio de López Muñoz $(1989,85,92,157)$ no que avaliou o comportamento lingüístico dos responsables da Igrexa católica (a de maior presencia en Galicia) o $85 \%$ dos cregos falan só ou preferentemente en galego, pero non no exercicio da súa profesión. Cando din misa o $85,9 \%$ nunca utiliza o galego; un $4,2 \%$ misa sempre en galego, mentres que un $1,8 \%$ di nesta lingua máis da metade das súas misas e un $8,2 \%$ a metade ou menos. Estas cifras dan como resultado final que o $70 \%$ das misas en Galicia se fan en castelán, o $22,8 \%$ en galego e en castelán e o $7,2 \%$ en galego.

\subsection{A CODIFICACIÓN DO GALEGO}

A nova situación legal do galego necesitaba para a súa normalización unha codificación gráfica e morfolóxica. A proposta máis completa de galego están- 
dar foi elaborada polo ILG-RAG (1982), convertida en normativa oficial en novembro do mesmo ano. Nela considérase que o galego é lingua románica autónoma fronte á súa consideración como variedade do portugués (AGAL 1983).

Desde finais da pasada década dos setenta foise elaborando un galego supradialectal, baseado na tradición literaria que vén do Rexurdimento do pasado século e no galego oral, pero sen castelanismos léxicos, que foron substituídos moitas veces polas correspondentes formas do galego medieval ou do portugués moderno (igrexa, Deus, pobo, por ex.) ou por formas de uso moi restrinxido en áreas marxinais (o caso de días da semana como mércores ou venres). Estas formas, como préstamos internos, hoxe forman parte do galego común ${ }^{8}$.

A Gramática de Alvarez Blanco/Regueira/Monteagudo (1986) supuxo un paso adiante considerable na descrición e na formalización dunha regras gramaticais básicas do galego como lingua románica autónoma. Na codificación do léxico o labor máis importante correspóndelles a Santamarina/González González (1990), do Instituto da Lingua Galega, ó igual cós autores da devandita gramática, que redactaron un vocabulario galego dunhas 50.000 palabras. O ILG e a RAG publicaron un Diccionario da Lingua Galega (1990) de só 12.000 entradas, ó que seguiu o Diccionario da Real Academia Galega (1997) dunhas 25.000 entradas. A LNL de 1983 outorgoulle á RAG a potestade de actualización da codificación do corpus do galego ${ }^{9}$.

\section{CONTACTO GALEGO-CASTELÁN: CAMBIO DE CÓDIGO E INTERFERENCIAS LINGÜÍSTICAS}

Os cambios de código, entendidos como o abandono circustancial que os falantes fan da súa lingua de instalación para asumiren outra lingua co fin de resolver unha situación comunicativa determinada (Silva-Valdivia 1994, 158) prodúcense tanto entre galegofalantes coma entre castelanfalantes. Estes cambios de código teñen catro causas principais, dúas delas comúns ós castelán e ós galegofalantes, a educación e o interese económico e profesional; unha terceira propia do troco do castelán polo galego, o respecto e a consideración; e unha cuarta, o prestixio social, que xustifica o cambio galego polo castelán (Hermida 1998).

\footnotetext{
${ }^{8}$ Sobre a planificación do corpus do galego cf. Herrero ValeiRo (1993), MontEagudo/SANTAmarina (1993), Monteagudo (1995) e Santamarina (1994). Sobre a posición e a consideración do galego na actual romanística cf. Fernandez Rei (1993) e (1996).

${ }^{9}$ No mercado existen diversos diccionarios que superan, con moito algún deles, as 35.000 entradas. É o caso dos diccionarios monolingües (galego-galego) de ALONSO ESTRAVIS (1986, 1995), ARES Vázquez (1986), Feixó Cid (1986), Rodríguez Alonso (1995) e Xove Ferreiro (1995) e do diccionario galego-castelán de MONTEAGUdo RoMero/García CANCELA (1988).
} 
Intereses profesionais e económicos explican o cambio de código de quen abandona circunstancialmente o seu idioma para empregar outro que considera que en determinadas circunstancias e ante determinadas persoas pode tirar un beneficio económico ou profesional. $\mathrm{O}$ troco inducido pola consideración e polo respecto prodúcese cando os castelanfalantes se dirixen a xente que pola súa idade ou polo seu aparente estado son tidos por descoñecedores do castelán, como ocorre con médicos que usan o galego cos pacientes máis vellos, pero usan o castelán con xente nova, aínda que esta inicie a interacción en galego.

Entre os galegofalantes un dos motivos que xustifica o cambio de código é o prestixio social. O crego que fala en galego cos fregueses e misa en castelán, o profesor galegofalante que ensina en castelán, os comerciantes que teñen o galego como lingua de expresión normal que se dirixen á clientela en castelán... todos eles fano para que o uso do galego non os delate como xente inculta e de procedencia rural.

A interferencia lingüística, ou uso inconsciente e permanente dunha estructura impropia dunha lingua condicionado por outra lingua coa que convive (Silva-Valdivia 1994, 165) afecta en Galicia ós dous idiomas en conflicto. A interferencia do galego no castelán de Galicia é moi evidente na entoación, cos tonemas propios do galego. Tamén o é no uso de vocais de grao medio abertas e pechadas e no de $n$ velar en contextos onde o castelán presenta unha alveolar (con aquella). A influencia castelá é clara nalgúns modelos fonéticos dos medios de comunicacións que usan o galego (Regueira 1994).

Na morfoloxía o sistema verbal é o máis interferido, con ausencia de tempos compostos, como por ex. llegué, llegara ( gal. cheguei, chegara; cast. llegué/he llegado, había llegado) ou con uso de perífrases con valores das galegas correspondentes no doy acabado (gal. non dou acabado, cast. no consigo acabar), hubo de morir (gal. houbo morrer, cast. estuvo a punto de morirse e non tuvo que morir) ou he de hacerte un regalo (gal. heiche facer un agasallo, cast. te haré un regalo e non tengo que hacerte un regalo). Hai moitos trazos sintácticos galegos no castelán de Galicia, como é o uso do pronome de solidariedade ( no te tengo, gal. non che teño, cast. no tengo ) ou de preposicións en construccións como tira con eso, llaman por ti (gal. tira con iso, llaman por $t i$; cast. tira eso, te llaman). No léxico os campos semánticos máis interferidos son os relativos á vida familiar e doméstica, caracterización física ou psicolóxica das persoas, animais e plantas propias do país e, en xeral, o léxico do campo e do mar (García 1976).

O influxo do castelán sobre o galego popular (despreciativamente denominado chapurrado e castrapo) afecta fundamentalmente ó léxico. Algúns castelanismos de uso xeral no galego popular (Dios, Iglesia, pueblo, siglo no canto de Deus, Igrexa, pobo, século) documéntanse xa na Idade Media. Outros máis recentes como pareja, conejo, juez (gal. parella, coello, xuíz) poden adaptarse á fonética galega (parexa, conexo, xuez), ben desprazando totalmente a forma autóctona, ben convivindo as dúas formas pero con especialización semántica (Noia Campos 1984, Graña Núñez 1993, González Seoane 1994). 
Entre as interferencias morfosintácticas do castelán, que se rexistran especialmente no galego de quen tivo o castelán como lingua inicial salientan as alteracións do xénero en formas como a sal, a leite, a mar, o auga (gal. o sal, o leite, o mar, a auga; cast. la sal, la leche, el/la mar, el agua), o uso de formas verbais como anduven, huben, había feito (gal. andei, houben, fixera; cast. anduve, hube, había hecho) ou a anteposición do pronome átono ó verbo en frases como llo dás, me chamas (gal. dásllo, chámasme; cast. se lo das, me llamas).

\section{REFERENCIAS BIBLIOGRÁFICAS}

AGAL [Associaçom Galega da Língua] (1983): Estudo crítico das normas ortográficas e morfológicas do idioma galego. Coruña.

Alonso ESTRAvís, Isaac (dir.) (1986): Dicionário da língua galega, 3 vols. Madrid: Alhena.

Alonso Estravís, Isaac (1995): Dicionário da língua galega. Santiago de Compostela: Sotelo Blanco.

Álvarez, Rosario; Regueira, Xosé-Luís; Monteagudo, Henrique (1986): Gramática galega. Vigo: Galaxia.

ARES VÁZquez, Ma Carme et alii (1986): Diccionario da lingua galega. Vigo: Xerais $\left(1990^{3}\right)$.

Chacón, Rafael (1979): "Diglosia e historia", in Grial, 93, 349-64.

Feixó CiD, Xosé C. (coord.) (1986): Diccionario da lingua galega, 3 vols. Vigo: Ir Indo.

FERnÁNDEZ ReI, Francisco (1990a): Dialectoloxía da lingua galega. Vigo: Xerais.

FERNÁNDEZ REI, Francisco (1990b): "Nacionalismo e dignificación da lingua galega no período 1972-1980", in A Trabe de Ouro 1, 43-71.

Fernández Rei, Francisco (1993): "La place de la langue galicienne dans les classifications traditionnelles de la Romania et dans les classifications standardologiques récentes", in Rodríguez Yáñez, Xoán Paulo (ed.): Plurilinguismes, 6 Sociolinguistique Galicienne. Paris.

FERnánDEZ ReI, Francisco (1996): “A posición do galego, lingua románica reemerxente", in Lorenzo, Ramón/Alvarez, Rosario: Homenaxe á profesora Pilar Vázquez Cuesta. Santiago de Compostela: Departamento de Filoloxía Galega/Universidade, 15-46.

FERNÁNDEZ REI, Francisco (1997): "Espagnol - galicien", in Goebl, Hans/Nelde, Peter H./Stary, Zdene(k/Wölck, Wolfgang: Kontaklinguistik. Contact Linguistics. Linguistique de contact. Ein internationales Handbuch zeitgenössischer Forschung. An International Handbook of Contemporary Research. Manuel international des recherches contemporaines. Vol. 2. Berlín/New York: Walter de Gruyter, 1285-95. 
FERnÁndeZ [RodrígueZ], Mauro (1978): "Bilingüismo y diglosia”, Verba 5, 375-91.

FERnÁndez Rodríguez, Mauro A.; Rodríguez Neira, Modesto A. (coords.) (1994): Lingua inicial e competencia lingüistica en Galicia. [A Coruña]: Real Academia Galega. Seminario de Sociolingüística.

Fernández Rodríguez, Mauro A.; Rodríguez Neira, Modesto A. (coords.) (1995a): Usos lingüísticos en Galicia. Compendio do II volume do Mapa Sociolingüistico de Galicia. [A Coruña]: Real Academia Galega. Seminario de Sociolingüística.

Fernández Rodríguez, Mauro A.; Rodríguez Neira, Modesto A. (coords.) (1995b): Addenda a Lingua inicial e competencia lingüistica en Galicia. [A Coruña]: Real Academia Galega. Seminario de Sociolinguística.

FreiXeIRo Mato, Xosé R. (1997): Lingua galega: normalidade e conflicto. Santiago de Compostela: Laiovento.

GarCía, Constantino (1976): "Interferencias lingüísticas entre gallego y castellano", Revista Española de Lingüística 6, 327-43.

GarCía Negro, Ma Pilar (1991): O galego e as leis. Aproximación sociolingüística. Vilaboa: Edicións do Cumio.

G[ONZÁleZ] BERAMENDI, Justo; NúÑeZ SeIXAS, Xosể M. (1995): $O$ nacionalismo galego. Vigo: A Nosa Terra.

GonzÁlez SeOAne, Ernesto (1994): "Variedade e empobrecemento do léxico", in Cadernos de Lingua 10, 89-102.

Graña NúÑEZ, Xosé (1993): Vacilacións, interferencias e outros "pecados" da lingua galega. Vigo: Ir Indo.

HERMIDA, Carme (1992): Os precursores da normalización. Defensa e reivindicación da lingua galega no Rexurdimento (1840-1891). Vigo: Xerais.

HeRMiDA, Carme (1995): "Contribución á historia do galego nos medios de comunicación. A prensa no século XIX”, en A Trabe de Ouro 20, 71-83.

HERMIDA, Carme (1998) (?): "Galician" (no prelo).

Herrero Valeiro, Mário J. (1993): “Guerre des graphies et conflit glottopolitique: lignes de discours dans la sociolinguistique galicienne”, in Rodríguez Yáñez, Xoán Paulo (ed.): Plurilinguismes 6 Sociolinguistique Galicienne. París.

ILG-RAG [Instituto da Lingua Galega - Real Academia Galega] (1982): Normas ortográficas e morfolóxicas do idioma galego. Vigo (12a ed. revisada 1995).

LÓPEZ MUÑoz, Daniel (1989): O idioma da Igrexa en Galicia. [Santiago de Compostela]: Consello da Cultura Galega.

Monteagudo Romero, Henrique (1985): "Aspectos sociolingüísticos do uso do galego, castelán e latín na Idade Media en Galicia", in Revista de Administración Galega 1, 85-108.

Monteagudo Romero, Henrique; García Cancela, Xermán (coords.) (1988): Diccionario normativo galego-castelán.

Monteagudo, Henrique (1991): "As leis, as letras e a lingua galega. Breve ollada retrospectiva", in Monteagudo, H. et alii: Contos da xustiza. Vigo: Ir Indo, 5-31. 
MONTEAGUDO, Henrique (1995) (ed.): Estudios de sociolingüistica galega. Sobre a norma do galego culto. Vigo: Galaxia.

Monteagudo, Henrique; Santamarina, Antón (1993): "Galician and Castilian in contact: historical, social and linguistic aspects", in Posner, Rebeca/Green, John N. (eds.): Trends in Romance linguistics Vol. 5. Bilingualism and linguistic conflict in Romance. Berlin/New York/Amsterdam: Mouton de Gruyter, 117-73.

Nola Campos, Ma Camino (1984): "Contribución ó estudio do léxico dos bilingües", Verba 11, 181-95.

Real Academia Galega (1997): Diccionario da Real Academia Galega. A Coruña/ Vigo: Real Academia Galega/Xerais/Galaxia.

RECALDE, Montserrat (1997): "La vitalidad etnolingüística gallega". Centro de Estudios sobre Comunicación Interlingüística e Intercultural/Departament de Teoria dels Llenguatges, Universitat de València, vol. 9.

RegueIRA, Xosé Luis (1994): "Modelos fonéticos e autenticidade lingüística", in Cadernos de Lingua 10, 37-60.

Rodríguez Alonso, Manuel (1995): Vieiro. Diccionario didáctico do galego. Madrid: SM.

Rodríguez Neira, Modesto; LóPez MarTínez, M. Sol (1988): O galego na Universidade. [Santiago de Compostela]: Consello da Cultura Galega.

Rojo, Guillermo (1981): "Conductas y actitudes lingüísticas en Galicia", in Revista española de lingüística 11/2, 269-310.

Roso, Guillermo (1982): "La situación lingüística gallega", in Revista de Occidente 10-11, 93-110.

Rubal Rodríguez, Xosé; RodríGuez Neira, Modesto (1987): $O$ galego no ensino público non universitario. [Santiago de Compostela]: Consello da Cultura Galega.

Rubal Rodríguez, Xosé; Veiga Martínez, Daniel; Arza Arza, Neves (1992): A lingua do alumnado e profesorado nas franxas occidentais de Asturias, León e Zamora. [Santiago de Compostela]: Consello da Cultura Galega.

[SANTAMaRina, Antón; GonzÁleZ GonZÁlez, Manuel (1990)] (coord.): Vocabulario ortográfico da lingua galega (versión provisional), 2 tomos. ILG/RAG.

Santamarina, Antón; Fernández Rei, Francisco (1992): "Dinamismo económico e identidade en Galicia", in A Trabe de Ouro 9, 21-33.

Santamarina, Antón (1994): "Lingua galega: norma e standard", in Holtus, Günter/Metzeltin, Michael/Schmitt, Christian (eds.): Lexikon der romanistischen Linguistik. Tübingen: Niemeyer, VI,2, 66-79 (Reproducido in Monteagudo (ed.) (1995) 53-98).

Silva-Valdivia, Bieito (1994): "Cambios de código, alternancias e interferencias linguísticas: unha perspectiva didáctica sociocomunicativa", in Silva-Valdivia, Bieito (ed.): Didáctica da lingua en situacións de contacto lingüístico. Santiago de Compostela: Instituto de Ciencias da Educación. Universidade.

SixireI PAREDES, Carlos (1988): A emigración. Vigo: Galaxia. 
VÁZQuez CuESTA, Pilar (1980): “Literatura gallega", in Historia de las literaturas hispánicas no castellanas. Madrid: Taurus, 621-896.

VILlaRES, Ramón (1984): A historia. Vigo: Galaxia.

Xove Ferreiro, Xosé (1995): Diccionario da lingua galega. Vigo: Obradoiro.

Xunta de Galicia (1997): Galicia 1997. 